\title{
ANALISIS RISIKO LIKUIDITAS PADA PT. BANK NEGARA INDONESIA (PERSERO) TBK
}

\author{
Putri Yanti, Yosep Eka Putra \\ Akademi Keuangan Perbankan "Pembangunan" (AKBP) Padang \\ putriyanti593@yahoo.com
}

\begin{abstract}
ABSTRACK
The purpose this research is to discuss about liquidity risk analysis at "Bank Negara Indonesia" (Persero) Tbk. The writer uses quantitative method. The type of data used is secondary data, which is obtained from published reports of "Bank Negara Indonesia" (Persero) Tbk the period 2016 to 2020. The result of this study indicate that the Cash Ratio can be said to be healthy because it is in accordance with Bank Indonesia regulations with an average ratio of 4,05\%. The Quick Ratio is in the healthy criteria because the average value is greater than 100\%. Loan to Deposit Ratio is in good condition because its value is below 75\%. This means that the bank is able to fulfill its obligations immediately with its liquid assets and is able to provide depositors requests when withdrawing funds so that the bank's liquidity risk is in a healty condition and well maintained.
\end{abstract}

Keywords : Cash Ratio, Quick Ratio and Loan to Deposit Ratio

\section{PENDAHULUAN}

Perkembangan siklus perekonomian global yang semakin maju menyebabkan antar perusahaan nasional dan internasional saling bersaing dalam meningkatkan kinerja yang maksimal dalam rangka mendapatkan sasaran yang ingin diperoleh. Salah satu lembaga usaha yang berperan penting bagi perekonomian adalah perbankan. Bank merupakan unit usaha yang sangat besar peranannya terhadap pertumbuhan perekonomian dan mendukung pembangunan nasional.

Kegiatan utama lembaga perbankan adalah sebagai wadah dalam hal simpan pinjam uang bagi masyarakat. Masyarakat yang kelebihan dana dapat menyimpan uang di bank dalam bentuk tabungan, giro dan deposito berjangka.

Bank menurut pasal 1 ayat (2) UU No. 10 Tahun 1998 yang merupakan perubahan atas UU No. 7 Tahun 1992 tentang perbankan adalah suatu lembaga usaha yang memperoleh dana dari kegiatan simpanan oleh masyarakat yang kelebihan dana dan kemudian memutarkan dana tersebut kepada masyarakat yang membutuhkan berupa fasilitas kredit dengan tujuan demi kesejahteraan hidup masyarakat banyak.

Perbankan adalah unit usaha yang berlandaskan kepercayaan dalam memberikan pelayanan. Selain itu bank juga diharapkan dapat bekerja dengan tingkat efisiensi yang tinggi dan mampu mengelola segala risiko dari setiap aktivitas yang dilakukannya.

Menurut (Siamat, 2004) risiko usaha bank merupakan risiko yang terjadi akibat tingkat pengembalian pendapatan yang kemungkinan tidak diterima dikemudian hari. Hal ini bisa disebabkan oleh terjadinya kredit macet, kesulitan dalam pendanaan jangka panjang, maupun perubahan suku bunga pasar yang tidak stabil. Beberapa risiko yang dapat terjadi dari aktivitas operasional bank yakni risiko likuiditas, risiko kredit, dan risiko solvabilitas (Habibie, 2017).

Menurut (Anggraeni, 2014) likuiditas adalah bagaimana kesanggupan bank membayar hutangnya dalam jangka waktu yang harus segera dibayar atau jangka 
pendek, memenuhi seluruh permintaan deposannya serta dapat memberikan permintaan kredit. Bank diharapakan dapat menjaga likuiditasnya dengan baik agar dapat mengurangi risiko likuiditas yang timbul karena bank mengalami kesulitan dalam melunasi hutang jangka pendeknya. Risiko likuiditas dapat diukur dengan menggunakan analisa rasio yakni Cash Ratio (CR), Quick Ratio (QR), dan Loan to Deposit Ratio (LDR) (Yusra, 2016).

Cash Ratio $(C R)$ merupakan indikator yang menggambarkan sejauh mana bank mampu memenuhi seluruh kewajibannya dengan menggunakan aset likuid seperti kas, saham dan obligasi. Quick Ratio (QR) yaitu analisa bagaimana bank mencukupi permintaan para nasabahnya dengan aset likuid yang dimiliki pada saat ditagih (Fitri \& Marlius, 2019). Menurut (Hardi \& Fernos, 2019) Loan to Deposit Ratio (LDR) merupakan gambaran mengenai jumlah pinjaman yang disalurkan dengan perbandingan total penerimaan bank oleh dana pihak ketiga.

Risiko kredit merupakan risiko yang terjadi dalam aktivitas pembiayaan atau kredit dengan membandingkan antara kredit macet dengan jumlah seluruh pinjaman (Kalixta Intan Christine, 2014). Menurut (Lisa, 2014) rasio yang berfungsi untuk menganalisa risiko kredit adalah Non Performing Loan (NPL) yaitu kesanggupan bank mengevaluasi dan mengelola segala kemungkinan risiko akibat debitur kesulitan dalam melunasi seluruh kewajibannya pada saat ditagih.

Menurut (Amelia \& Afriyeni, 2019) rasio solvabilitas adalah kesanggupan suatu bank membiayai hutang yang bersifat jangka panjang baik terhadap modal sendiri maupun modal pinjaman. Rasio solvabilitas dapat dihitung dengan indikator rasio hutang terhadap ekuitas (Debt to Total Equity Ratio) dan total hutang terhadap total aktiva (Debt to Total Asset Ratio). Debt to Total Equity Ratio yaitu rasio yang diperoleh dengan membandingkan antara total hutang dengan ekuitas pemilik. Sedangkan Debt to Total Asset Ratio adalah indikator rasio yang bertujuan untuk mengetahui total hutang dan total kekayaan perusahaan.

Dalam menganalisa risiko bank maka dapat dilakukan dengan cara menganalisa laporan keuangan yang disajikan oleh perusahaan selama jangka waktu tertentu. Menurut (Badria \& Marlius, 2019) laporan keuangan merupakan data yang menyajikan mengenai keuangan suatu perusahaan yang berguna bagi pemangku kepentingan (stake holder) selama jangka waktu tertentu.

PT. Bank Negara Indonesia merupakan sebuah lembaga keuangan yang sangat berperan penting bagi masyarakat. Bank memberikan jasa baik dari segi penghimpunan dana, penyaluran berbagai jenis kredit seperti kredit bantuan modal kerja, kredit konsumtif, kredit investasi dan juga layanan jasa lainnya. Bank memberikan jumlah permintaan kredit dalam jumlah yang sangat besar sehingga risiko kredit bermasalah juga tinggi. Oleh sebab itu bank perlu memitigasi segala risiko yang dapat terjadi pada suatu waktu agar operasional bank tidak terganggu.

Menurut (Gustini \& Afriani, 2015) faktor internal dan eksternal perbankan yang semakin maju dan meningkat menyebabkan tingkat risiko perbankan yang juga tinggi sehingga diperlukannya praktek tata kelola bank yang baik. Manajamen risiko diperlukan agar kepercayaan masyarakat terhadap bank tinggi dan likuiditas bank dalam keadaan yang sehat.

Penelitian ini bertujuan untuk mengetahui bagaimana risiko likuiditas pada PT. BNI yakni mengukur sejauh mana kemampuan bank dalam membayar kewajiban jangka pendeknya dengan menggunakan alat likuid yang dimiliki serta kemampuan bank dalam memenuhi permintaan deposannya pada saat melakukan penarikan dana.

Berikut perkembangan Cash Ratio, Quick Ratio, dan Loan to Deposit Ratio PT. Bank Negara Indonesia (Persero) Tbk periode 2016-2020. 


\section{Tabel 1}

Perkembangan Cash Ratio, Quick Ratio dan Loan to Deposit Ratio

PT. BNI (Persero) Tbk

Periode 2016-2020

\begin{tabular}{cccccc}
\hline Keterangan & \multicolumn{5}{c}{ Tahun } \\
& $\mathbf{2 0 1 6}$ & $\mathbf{2 0 1 7}$ & $\mathbf{2 0 1 8}$ & $\mathbf{2 0 1 9}$ & $\mathbf{2 0 2 0}$ \\
\hline CR & $35,87 \%$ & $38,55 \%$ & $34,30 \%$ & $33,32 \%$ & $33,17 \%$ \\
QR & $335,56 \%$ & $232,76 \%$ & $328,85 \%$ & $283,01 \%$ & $303,53 \%$ \\
LDR & $75,17 \%$ & $71,74 \%$ & $74,57 \%$ & $75,98 \%$ & $74,99 \%$ \\
\hline
\end{tabular}

Sumber: $\underline{w w w . o j k . g o . i d}$

Berdasarkan tabel 1 diatas menunjukkan bahwa perkembangan risiko likuiditas dengan menggunakan indikator Cash Ratio dimana pada tahun 2016 sampai 2020 rasionya naik turun. Dengan kata lain alat likuid yang dimiliki bank mampu membayar kewajiban jangka pendeknya yang harus segera dibayar pada saat jatuh tempo. Dimana nilai Cash Ratio rata-rata besar dari 4,05\%. Quick Ratio bank dapat dikatakan sehat artinya kas yang dimiliki oleh bank dapat memenuhi hutang lancarnya dengan rata-rata nilai Quick Ratio besar dari $100 \%$. Sedangkan Loan to Deposit Ratio bank dapat dikatakan sehat dengan nilai rata-ratanya kurang dari $75 \%$. Artinya bank mampu dengan baik memenuhi permintaan deposannya pada saat melakukan penarikan dana.

\section{LANDASAN TEORI}

\section{Pengertian Bank}

Bank merupakan suatu institusi yang aktivitasnya bergerak dalam bidang keuangan, dengan kata lain bank memiliki peran penting dalam meningkatkan pertumbuhan dan perkembangan perekonomian suatu negara. Menurut UU No. 10 Tahun 1998 pasa 1 ayat (2) atas perubahan UU No. 7 Tahun 1992 mengenai perbankan, bank merupakan suatu lembaga keuangan yang memperoleh sumber dana dari aktivitas simpan dan pinjam uang oleh masyarakat dalam upaya menunjang pertumbuhan perekonomian masyarakat banyak.

\section{Jenis-Jenis Bank}

Menurut (Kasmir, 2001) dilihat dari fungsinya bank terdiri dari, yakni :

1. Bank Umum

Bank umum adalah lembaga yang melakukan aktivitas operasional berdasarkan prinsip konvensional dan atau sesuai syariat yang dapat membantu dalam proses lalu lintas pembayaran.

2. Bank Perkreditan Rakyat (BPR)

Merupakan bank yang ruang lingkupnya lebih kecil dari pada bank umum. Dimana BPR melakukan aktivitas operasional secara konvensional atau sesuai syariah islam namun tidak dapat melakukan pemberian jasa dalam proses lalu lintas pembayaran.

Fungsi Bank

Menurut ((IBI), 2018) fungsi dan peranan bank secara umum terdiri dari yaitu :

1. Agent of trust

Artinya bank sebagai penghimpun dan penyalur dana harus berlandaskan kepercayaan. Kepercayaan adalah aspek utama yang menentukan agar masyarakat mau menyimpan dananya dibank.

2. Agent of development

Artinya lembaga yang menyediakan dana untuk menunjang kegiatan pembangunan.

3. Agent of services

Artinya dalam aktivitasnya bank memberikan penawaran jasa untuk memudahkan masyarakat dalam memenuhi kebutuhannya. 


\section{Pengertian dan Tujuan Laporan Keuangan}

Menurut (Kasmir, 2014) "laporan keuangan adalah laporan yang menunjukkan informasi keuangan perusahaan selama jangka waktu tertentu”. Laporan keuangan merupakan suatu proses penyajian data keuangan perusahaan yang biasanya terdiri dari necara, laporan laba-rugi, dan laporan perubahan modal ((IAI), 2008).

Secara umum laporan keuangan memiliki tujuan untuk menunjukkan gambaran tentang keadaan keuangan suatu perusahaan suatu waktu biasanya dilaporkan dalam periode tertentu (Kasmir, 2012).

\section{Jenis-Jenis Laporan Keuangan}

Jenis laporan keuangan yang umum digunakan, yaitu sebagai berikut (Kasmir, 2012) :

1. Laporan laba rugi

Laporan yang menggambarkan penghasilan dari total penjualan, laba yang diperoleh oleh perusahaan serta dikurangi dengan biaya-biaya yang dikeluarkan selama periode tertentu.

2. Laporan perubahan modal

Laporan mengenai tingkat perubahan yang terjadi pada modal yang dimiliki oleh suatu perusahaan.

3. Neraca

Laporan mengenai kekayaan, hutang, dan modal suatu perusahaan yang menjelaskan tentang posisi keuangan usaha pada jangka waktu tertentu.

4. Laporan arus kas

Laporan yang menggambarkan aliran pendapatan dan pengeluaran atas uang tunai (kas) suatu perusahaan.

5. Laporan catatan atas laporan keuangan

Laporan yang memberikan keterangan lain yang diperlukan bagi pengguna laporan keuangan.

\section{METODE PENELITIAN}

1. Metode Pengumpulan Data

Metode yang digunakan dalam pengumpulan data adalah dengan Riset Kepustakaan (Library Research). Riset kepustakaan dilakukan dengan cara mempelajari buku-buku, makalah-makalah, artikel, bacaan serta laporan publikasi yang berhubungan dengan objek penelitian.

2. Metode Analisis Data

Dalam menganalisa data, metode penelitian yang digunakan yaitu analisa data kuantitatif dengan menggunakan alat-alat rasio keuangan mengenai risiko likuiditas pada PT. BNI (Persero) Tbk.

\section{HASIL DAN PEMBAHASAN}

\section{Analisa Risiko Likuiditas (Liquidity Risk)}

Menurut (Kasmir, 2008) risiko likuiditas adalah risiko bagi bank apabila gagal membayar kewajibannya terhadap deposannya dengan menggunakan aset yang paling likuid yang ada. Indikator yang digunakan untuk mengukur rasio risiko likuiditas adalah :

\section{a. Cash Ratio (CR)}

Merupakan alat likuid yang dimiliki oleh bank terhadap total dana pihak ketiga yang akan jatuh tempo atau segera harus dibayar. Rasio kas dapat diukur dengan menggunakan rumus yaitu : 
$\mathrm{CR}=\frac{\text { Kas }}{\text { Hutang Lancar }} \times 100 \%$

Kriteria penilaian cash ratio menurut SK DIR BI No. 30/12/KEP/DIR tanggal 30 April 1997 adalah sebagai berikut :

Tabel 2

Kriteria Penilaian Cash Ratio

\begin{tabular}{cc}
\hline Kriteria & Standar \\
\hline Sehat & $>=4,05 \%$ \\
Cukup sehat & $>=3,30 \%-<4,05 \%$ \\
Kurang sehat & $>=2,55 \%-<3,30 \%$ \\
Tidak sehat & $0<2,55 \%$ \\
\hline
\end{tabular}

\begin{tabular}{ccccc}
\hline \multicolumn{5}{c}{ Tabel 3 } \\
& \multicolumn{5}{c}{$\begin{array}{c}\text { Perkembangan Cash Ratio } \\
\text { PT. BNI (Persero) Tbk } \\
\text { Tahun 2016-2020 } \\
\text { (Dalam Jutaan Rupiah) }\end{array}$} \\
\hline No & Tahun & Alat Likuid & Hutang Lancar & Cash Ratio (CR) \\
& \multicolumn{5}{c}{ (1) } & $\mathbf{( 2 )}$ & $\mathbf{( 1 : 2 ) \times 1 0 0 \%}$ \\
\hline 1 & 2016 & 149.037 .423 & 415.423 .235 & $35,87 \%$ \\
2 & 2017 & 189.771 .280 & 492.329 .054 & $38,55 \%$ \\
3 & 2018 & 188.264 .852 & 548.819 .838 & $34,30 \%$ \\
4 & 2019 & 192.066 .591 & 576.348 .502 & $33,32 \%$ \\
5 & 2020 & 211.530 .778 & 637.772 .986 & $33,17 \%$ \\
\hline
\end{tabular}

Sumber : www.ojk.go.id, data olahan

Alat Likuid = Kas + Antar Bank Aktiva

Hutang Lancar $=$ Kewajiban Segera + DPK

Tahun 2016

$C R=\frac{149.037 .423}{415.423 .235} \times 100 \%$

Artinya, bank mampu memenuhi kewajiban jangka pendeknya menggunakan alat likuid yang dimiliki oleh bank tersebut dengan CR sebesar $35,87 \%$. Hal ini menunjukkan bahwa pada tahun 2016 cash ratio bank dikatakan sehat karena besar dari 4,05\%. Selanjutnya pada tahun 2017 sebesar $38,55 \%$ terjadi peningkatan daripada tahun sebelumnya yang juga menunjukkan bank dalam kondisi yang sehat. Kemudian tahun 2018 sampai dengan tahun 2020 terjadi penurunan tetapi masih besar dari batas ketentuan BI mengenai kriteria cash ratio yakni 4,05\%

b. Quick Ratio (QR)

Merupakan kemampuan suatu bank dalam membayar hutang lancar dengan menggunakan aktiva lancar yang dimiliki (Astuti Rani, 2018). Rasio cepat dapat diukur dengan menggunakan rumus yaitu :

$Q R=\frac{\text { Alat Likuid }}{\text { Hutang Lancar }} \times 100 \%$

Kriteria penilaian Quick Ratio menurut SE BI No. 6/23/DPNP Tahun 2009 adalah sebagai berikut : 


\section{Tabel 4}

Kriteria Penilaian Quick Ratio

\begin{tabular}{cc}
\hline Kriteria & Standar \\
\hline Sehat & $>100 \%$ \\
Cukup sehat & $80 \%-90 \%$ \\
Kurang sehat & $60 \%-70 \%$ \\
Tidak sehat & $40 \%-50 \%$ \\
Sangat tidak sehat & $20 \%-30 \%$ \\
\hline
\end{tabular}

Tabel 5

Perkembangan Quick Ratio

PT. BNI (Persero) Tbk

Tahun 2016-2020

(Dalam Jutaan Rupiah)

\begin{tabular}{ccccc}
\hline No & Tahun & $\begin{array}{c}\text { Alat Likuid } \\
\text { (Kas) }\end{array}$ & Hutang Lancar & Quick Ratio \\
& & $(\mathbf{1})$ & $(\mathbf{2})$ & $\mathbf{( 1 : 2 ) \times 1 0 0 \%}$ \\
\hline 1 & 2016 & 10.991 .946 & 3.275 .668 & $335,56 \%$ \\
2 & 2017 & 11.330 .043 & 4.867 .547 & $232,76 \%$ \\
3 & 2018 & 13.681 .004 & 4.160 .295 & $328,85 \%$ \\
4 & 2019 & 14.922 .678 & 5.272 .805 & $283,01 \%$ \\
5 & 2020 & 16.878 .580 & 5.560 .702 & $303,53 \%$ \\
\hline
\end{tabular}

Sumber : www.ojk.go.id, data olahan

Alat likuid $=$ Kas

Hutang lancar $=$ Kewajiban segera

Tahun 2016

$Q R=\frac{10.991 .946}{3.275 .668} \times 100 \%$

Artinya, bank mampu membayar kewajibannya dengan menggunakan alat likuid yang dimiliki oleh bank. Hal ini menunjukkan bank dikatakan sehat karena QR berada diatas 100\%. Pada tahun 2017 terjadi penurunan sebesar 232,76\%. Tahun 2018 naik sebesar 328,85\%. Kemudian tahun 2019 turun sebesar $283,01 \%$ dan tahun 2020 kembali meningkat sebesar 303,53\%. Rasio QR bank BNI bersifat fluktuatif setiap tahunnya tetapi tidak kurang nilainya dari $100 \%$ dengan kriteria sehat.

c. Loan to Deposit Ratio (LDR)

Merupakan rasio untuk mengukur kemampuan bank dalam membayar kembali permintaan nasabahnya yang telah menanamkan dananya dengan pinjaman yang diberikan oleh bank kepada debiturnya. Rumus yang digunakan untuk mengukur rasio LDR adalah :

$L D R=\frac{T \text { Total Loans }}{\text { Total Deposit }} \times 100 \%$

Kriteria penilaian Loan To Deposit Ratio (LDR) menurut SE BI No. 6/23/DPNP Tahun 2004 adalah sebagai berikut : 
Tabel 6

Kriteria Penilaian Loan To Deposit Ratio

\begin{tabular}{cc}
\hline Keterangan & Kriteria \\
\hline Sangat sehat & LDR $\leq 75 \%$ \\
Sehat & $75 \%<\mathrm{LDR} \leq 85 \%$ \\
Cukup sehat & $85 \%<\mathrm{LDR} \leq 100 \%$ \\
Kurang sehat & $100 \%<\mathrm{LDR} \leq 120 \%$ \\
Tidak sehat & $\mathrm{LDR}>120 \%$ \\
\hline
\end{tabular}

\section{Tabel 4}

Perkembangan Loan To Deposit Ratio (LDR) PT. BNI (Persero) Tbk

Tahun 2016-2020

(Dalam Jutaan Rupiah)

\begin{tabular}{ccccc}
\hline No & Tahun & $\begin{array}{c}\text { Kredit Yang } \\
\text { Diberikan } \\
(\mathbf{1})\end{array}$ & Dana Pihak Ketiga & LDR \\
\hline 1 & 2016 & 372.621 .478 & $\mathbf{( 2 )}$ & $\mathbf{( 1 : 2 ) \times 1 0 0 \%}$ \\
2 & 2017 & 417.151 .310 & 595.696 .796 & $75,17 \%$ \\
3 & 2018 & 483.421 .821 & 648.248 .619 & $71,74 \%$ \\
4 & 2019 & 522.750 .099 & 687.973 .903 & $75,57 \%$ \\
5 & 2020 & 551.786 .774 & 735.828 .041 & $74,99 \%$ \\
\hline
\end{tabular}

Total Loans $=$ Kredit yang diberikan

DPK = Tabungan + Deposito + Giro + Modal

Tahun 2016

$L D R=\frac{372.621 .478}{495.696 .796} \times 100 \%$

Artinya, kemampuan PT. BNI dalam memenuhi kewajiban jangka pendeknya pada tahun 2016 sebesar 75,17\%. Tahun 2017 mengalami penurunan sebesar 71,74\%. Kemudian tahun 2018 naik sebesar 74,57\%. Selanjutnya tahun 2018 naik lagi sebesar 75,98\% dan tahun 2020 kembali turun sebesar 74,99\%. Hal ini menunjukkan bahwa bank dikatakan sehat karena nilai LDR sesuai dengan ketentuan BI yakni kurang dari $75 \%$.

\section{SIMPULAN}

Berdasarkan hasil pembahasan yang dilakukan pada bab sebelumnya, maka dapat ditarik kesimpulan bahwa analisa risiko likuiditas dengan menggunakan analisa Cash Ratio, Quick Ratio, dan Loan To Deposit Ratio pada PT. Bank Negara Indonesia (Persero) Tbk pada periode 2016 sampai tahun 2020 adalah sebagai berikut :

1. Cash Ratio rata-rata besar dari ketentuan Bank Indonesia yakni $4,05 \%$ artinya kemampuan bank dapat dikatakan baik dalam memenuhi kewajiban lancarnya dengan menggunakan alat likuid yang dimiliki.

2. Quick Ratio rata-rata diperoleh nilai rasionya besar dari $100 \%$ artinya bank dapat dikatakan baik dalam membayar kewajiban lancarnya dengan menggunakan aktiva lancar yang dimiliki.

3. Loan To Deposit Ratio dapat dikatakan berada dalam kondisi yang sehat dengan rata-rata nilai rasionya tidak melebihi batas ketentuan BI yakni $<75 \%$ artinya bank dapat memenuhi seluruh permintaan deposannya pada saat melakukan penarikan dana. 


\section{UCAPAN TERIMA KASIH}

Terimakasih penulis sampaikan kepada PT. Bank Negara Indonesia (Persero) Tbk.

\section{DAFTAR PUSTAKA}

(IAI), I. A. I. (2008). Standar Akuntansi Keuangan (Kedua). Salemba Empat.

(IBI), I. B. I. (2018). Menguasai Fungsi Kepatuhan Bank (Edisi Revi). PT Gramedia Pustaka Utama.

Amelia, I., \& Afriyeni, A. (2019). Analisis Kinerja Keuangan Berdasarkan Rasio Solvabilitas Pada PT. Bpd Sumatera Barat. 2-8. https://doi.org/10.31219/osf.io/tsrzw

Anggraeni, R. (2014). Analisis Pengelolaan Kredit Untuk Meningkatkan Likuiditas Dan Profitabilitas (Studi Pada PT. BPR Wlingi Pahala Pakto). Jurnal Administrasi Bisnis S1 Universitas Brawijaya, 12(2), 1-10.

Astuti Rani, P. Y. E. (2018). Analisis Likuiditas, Dan Solvabilitas Pada Pt. Bank Perkreditan Rakyat Jorong Kampung Tangah Pariaman. 1-11. 2-8

Badria, M., \& Marlius, D. (2019). Analisis Rasio Likuiditas Pada PT. Bank Perkreditan Rakyat (Bpr) Lengayang. 2-3. https://doi.org/10.31219/osf.io/esvb7

Fitri, H. Y., \& Marlius, D. (2019). Analisis Rasio Likuiditas Pada PT. Bank Perkreditan Rakyat (Bpr) Nagari Kasang. 2-7. https://doi.org/10.31219/osf.io/bcs73

Gustini, D. W., \& Afriani, S. (2015). Analisis Manajemen Risiko Pada Kantor Pusat PT. Bank Bengkulu. EKOMBIS REVIEW: Jurnal Ilmiah Ekonomi Dan Bisnis, 2(1), 105-121. https://doi.org/10.37676/ekombis.v2i1.8

Habibie, A. (2017). Risiko Likuiditas dan Risiko Solvabilitas Terhadap Profitabilitas Bank. Jurnal Mutiara Akuntansi, 2(1), 1-16. https://doi.org/10.13140/RG.2.2.15229.26081

Hardi, J., \& Fernos, J. (2019). Analisis Ldr Dan Npl PT. Bank Nagari Cabang Pembantu Tarusan Kabupaten Pesisir Selatan. 1-2. https://doi.org/10.31227/osf.io/5dtm7

Kalixta Intan Christine, J. R. (2014). Analisis Resiko Perbankan Pada Bankaltim. 3-5.

Kasmir. (2014). Bank dan Lembaga Keuangan Lainnya. Raja Grafindo Persada.

Lendriani, L. \& Marlius, D. (2021). Analisis Rasio Likuiditas Pada PT. Bank Pembangunan Daerah Sumatera Barat. https://doi.org/10.31219/osf.io/ep2wn

Lisa, R. C. (2014). Pengaruh Risiko Kredit, Risiko Likuiditas dan Risiko Tingkat Bunga Terhadap Profitabilitas (Studi Empiris pada Perusahaan Perbankan Terdaftar di Bursa Efek Indonesia). 2-6.

Putra, E. Y. (2019). Analisis Loan to Deposit Ratio dan Non Performing Loan pada PT Bank Pembangunan Daerah Sumatera Barat Cabang Pembantu Aur Kuning. 110.

Ramadanti, A. Z., \& Dona, E. (2019). Analisis Rasio Likuiditas, Solvabilitas dan Profitabilitas pada Bank Nagari Pusat. 1-9.

Siamat, D. (2004). Manajemen Lembaga Keuangan (Keempat). Fakultas Ekonomi Universitas Indonesia Jakarta.

Yusra, I. (2016). Kemampuan Rasio Likuiditas dan Solvabilitas dalam Memprediksi Laba Perusahaan: Studi Empiris pada Perusahaan Telekomunikasi. Jurnal Benefita, 1(September), 15-23. 